\title{
Performance Analysis of Magnesium Phosphate Cement Mortar Containing Grinding Dust
}

\author{
Daniel Véras Ribeiro*, Márcio Raymundo Morelli \\ Departamento de Engenharia de Materiais, Universidade Federal de São Carlos - UFSCar \\ Rodovia Washington Luis, Km 235, 13565-905 São Carlos - SP, Brazil
}

Received: April 1, 2008, Revised: March 11, 2009

\begin{abstract}
Magnesium phosphate cement materials are formed by reacting magnesium oxide with water-soluble phosphates such as monoammonium dihydrogen phosphate (ADP), which solidifies at ambient temperature through the formation of hydrated phases in the material. Cylindrical specimens of magnesium phosphate cement were molded and varying amounts ( 0 to $30 \%$ weight) of grinding dust were added to the ceramic matrices. The influence of the addition of grinding dust on the characteristics of the mortars in terms of microstructure (SEM), mechanical strength and capillary water absorption was verified. The results obtained proved very satisfactory for the use of this waste as an additive in magnesium phosphate mortars.
\end{abstract}

Keywords: magnesium phosphate cement (MPC,) mortar, grinding dust, mechanical strength, absorption

\section{Introduction}

Phosphate cements possess mechanical and chemical properties that are superior to those of ordinary hydraulic (Portland) cements, $\mathrm{OPC}$, in general, thanks to innovations in their processing and microstructural handling and to compositional modifications. The bonds in such chemically bonded phosphate ceramics (CBPCs) is a mixture of ionic, covalent and van der Waals bonds, with a predominance of ionic and covalent bonds; in traditional cement hydration products, van der Waals and hydrogen bonds predominate ${ }^{1,2,3}$.

The reaction between a reactive form of magnesia and acid ammonium phosphate is very rapid and exothermic, and the materials cannot be practically used as such. Thus, the use of calcined or deadburned magnesia is suggested. Today's commercial materials are formulated with many inexpensive inert materials such as sand, fly ash, etc. to control the rate of reaction or setting time while simultaneously providing high early compressive strength. Phosphate cements for commercial applications are generally based on reactions between a metallic oxide and an acid salt or derivative of phosphoric acid ${ }^{1}$

Immediately upon mixing the raw materials at ambient temperature, exothermic reactions occur and ammonium and magnesium phosphate phases are formed. These phases are hydrated and insoluble in water.

The main product of these reactions is a crystalline phase called struvite $\left(\mathrm{NH}_{4} \mathrm{MgPO}_{4} \cdot 6 \mathrm{H}_{2} \mathrm{O}\right)$, which results from the following reaction (1):

$$
\mathrm{MgO}+\mathrm{NH}_{4} \mathrm{H}_{2} \mathrm{PO}_{4}+5 \mathrm{H}_{2} \mathrm{O} \rightarrow \mathrm{MgNH}_{4} \mathrm{PO}_{4} \cdot 6 \mathrm{H}_{2} \mathrm{O}
$$

Other phases such as dittmarite $\left(\mathrm{NH}_{4} \mathrm{MgPO}_{4} \cdot \mathrm{H}_{2} \mathrm{O}\right)$, schertelite $\left[\left(\mathrm{NH}_{4}\right)_{2} \mathrm{MgH}_{2}\left(\mathrm{PO}_{4}\right)_{2} 4 \mathrm{H}_{2} \mathrm{O}\right]$, and stercorite $\left[\mathrm{Na}\left(\mathrm{NH}_{4}\right) \mathrm{HPO}_{4} \cdot 4 \mathrm{H}_{2} \mathrm{O}\right]$ are ordinarily observed during hydration, while hanaite $\left[\left(\mathrm{NH}_{4}\right)_{2} \mathrm{Mg}_{3}\left(\mathrm{HPO}_{4}\right)_{4} 8 \mathrm{H}_{2} \mathrm{O}\right]$, newberyite $\left[\mathrm{MgHPO}_{4} \cdot 3 \mathrm{H}_{2} \mathrm{O}\right]$ and other phosphate hydrates are found less frequently ${ }^{4}$.

Struvite is a thermally stable phase in air up to a temperature of $55{ }^{\circ} \mathrm{C}$, at which point it decomposes through the loss of $\mathrm{H}_{2} \mathrm{O}$ and $\mathrm{NH}_{3}$ molecules from its structure, forming an amorphous composition that corresponds chemically to $\mathrm{MgHPO}_{4}$. In the presence of water at ambient temperature, this composition can be rehydrated, forming the original phase (struvite) and other amorphous and/or crystalline phases.

Struvite and dittmarite are chemically and structurally similar and the transformation of one into the other does not cause any microstructural damage to molded specimens ${ }^{5}$. Dittmarite is the predominant phase when the reaction is fast, while struvite predominates when the reaction rate is slow 5 .

$$
\begin{aligned}
& \left(\mathrm{NH}_{4}\right)_{2} \mathrm{Mg}\left(\mathrm{HPO}_{4}\right)_{2} \cdot 4 \mathrm{H}_{2} \mathrm{O}+\mathrm{MgO}+7 \mathrm{H}_{2} \mathrm{O} \rightarrow \\
& 2\left(\mathrm{NH}_{4}\right) \mathrm{MgPO}_{4} \cdot 6 \mathrm{H}_{2} \mathrm{O}
\end{aligned}
$$

A recent study by Soudée and Péra ${ }^{4}$ suggests a mechanism of formation of these materials, whereby, immediately following the addition of water to the mixture, the ADP goes into solution up to saturation while magnesia starts to be wetted. The drop in $\mathrm{pH}$ that occurs during this period leads to the dissociation of magnesia through an acid-base reaction. Crystallization of the hydrate phases begins when $\mathrm{Mg}^{+2}$ ions react with six molecules of water to form $\mathrm{Mg}\left(\mathrm{H}_{2} \mathrm{O}\right)_{6}^{+2}$ compounds. These compounds replace water molecules in the wetting process of magnesia. Their size prevents new water molecules from being adsorbed onto the $\mathrm{MgO}$ surface. The $\mathrm{Mg}\left(\mathrm{H}_{2} \mathrm{O}\right)_{6}^{+2}$ complexes remain attached to the surface, covering it progressively. $\mathrm{PO}_{4}^{3-}$ and $\mathrm{NH}_{4}{ }_{4}$ ions and $\mathrm{Mg}\left(\mathrm{H}_{2} \mathrm{O}\right)_{6}{ }^{+2}$ complexes can therefore develop a struvite network. Wagh and Jeong ${ }^{3}$ considered that the kinetics of these transformations is very similar to that of the conventional sol-gel process of ceramics fabrication. Figure 1 gives a step-by-step illustration of the kinetics of CBPC formation.

- Dissolution of oxides and formation of sols by hydrolysis

When metal oxides are stirred into an acid solution, they dissolve slowly, releasing their own metal which contains cations and oxygencontaining anions (Figure 1a - dissolution step). The cations react with water molecules and form positively charged "aquosols" by hydrolysis (Figure 1b-hydration step). Dissolution and hydrolysis are the controlling steps in the formation of CBPCs.

- Acid-base reaction and formation of gel by condensation

Sols react with aqueous phosphate anions (Figure 1c) to form hydrophosphate salts, while the protons and oxygen react to form water. The newly formed hydrophosphate salts make up a network 


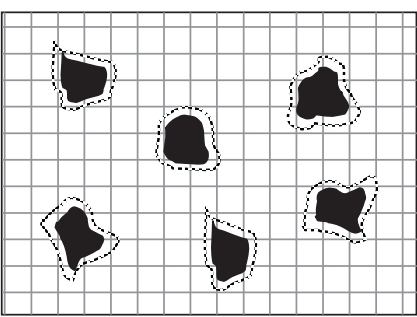

(a)

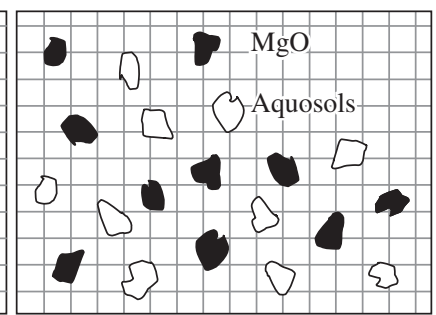

(b)

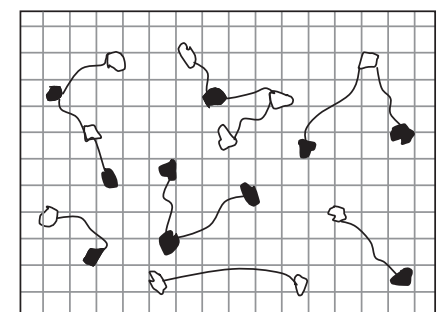

(c)

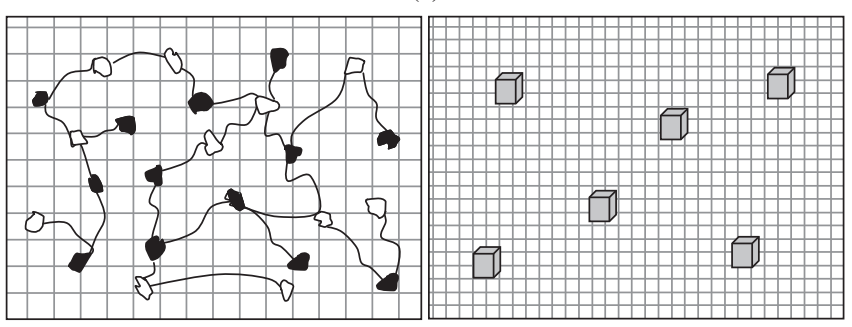

(d)

(e)

Figure 1. Scheme of the formation of CBPCs (chemically bonded phosphate ceramics): a) Dissolution of oxides; b) formation of aquosols; c) acid-base reaction and condensation; d) percolation and formation of gel; e) crystallization and saturation of gel into a ceramic ${ }^{3}$.

of molecules in the aqueous solution, leading to the formation of a gel (Figure 1d).

- Saturation and crystallization of the gel into a ceramic

As the reaction proceeds, this process introduces increasing amounts of reaction products into the gel, which is thus thickened. When sufficiently thick, the gel crystallizes around the unreacted core of each grain of the metal oxide, forming a well-connected crystal lattice that grows into a monolithic ceramic (Figure 1e) ${ }^{3}$.

Ever growing industrial activity around the world and the lack of efficient waste management programs means that increasing amounts of wastes are generated without their being utilized or disposed of correctly, leading to environmental problems that endanger the quality of life of future generations. A good part of these wastes is hazardous, containing elements harmful to human health and that contaminate soil and water tables. Until just a few years ago, the world produced only a few kilograms of wastes per inhabitant each year. Today, however, highly industrialized countries such as Germany and France produce about 4 tons/inhabitant/year, and the average volume of waste produced in Brazil's largest cities is currently about 0.95 tons/inhabitant/year ${ }^{6}$.

Because of the diversity of the physicochemical compositions of liquid effluents, no single solidification and stabilization technology can be used to successfully treat and dispose of these wastes. The stabilization of such wastes requires their contaminants be immobilized effectively. These contaminants are often volatile compounds and hence cannot be treated effectively by high-temperature processes. This critical need for a low-temperature treatment and stabilization technology to effectively treat secondary wastes generated by hightemperature treatment processes and wastes that are not amenable to thermal treatment was the main motivation for the development of chemically bonded phosphate ceramics (CBPCs) $)^{7}$. Once developed, CBPCs have found their niche applications in treating most difficult wastes such as salts, ashes, liquids and sludges.

The major attraction of this new moldable type of ceramics is that reasonable mechanical strength and excellent hardness can be achieved by processing the material without sintering, an operation that increases the product's final cost because it consumes more energy and takes place at high temperatures ${ }^{7,8}$. This type of cement is economically and technologically attractive because it combines the advantage of low energy processing of traditional cements with the physical properties of advanced ceramics that allow for high technology applications. Compared with polymers, these cements possess other advantages, i.e., they are nontoxic and nonflammable ${ }^{8}$.

Sant'anna and Morelli ${ }^{9,10}$ found that magnesium phosphate cements are porous and composed predominantly of nanometric pores which result from the hydration process. They obtained a material with porosity and mechanical strength unheard of in many manufactured materials. These are cements that not only have excellent mechanical properties but are also easily molded. They can be manufactured with the incorporation of pigment, and accept polymeric paint and coatings that adhere to various materials, particularly to steel, thus opening up a wide range of possibilities for combinations in metallic structures $^{5,11}$.

\section{Materials and Methods}

\subsection{Materials}

\subsubsection{Magnesium oxide $(\mathrm{MgO})$}

In the present study, we used a commercial deadburned magnesium oxide calcined at $1,600{ }^{\circ} \mathrm{C}$, with a $\mathrm{MgO}$ content of 88 to $93 \%$. Deadburned calcined magnesia is produced at temperatures above $1,400{ }^{\circ} \mathrm{C}$ and is characterized by its low chemical reactivity and high resistance to basic slags. The magnesium oxide presented a specific surface area of $0.81 \mathrm{~m}^{2} . \mathrm{g}^{-1}$, unitary mass of $1.34 \mathrm{~kg} \cdot \mathrm{dm}^{-3}$ and specific gravity of $3.61 \mathrm{~kg} . \mathrm{dm}^{-3}$.

\subsubsection{Ammonium Dihydrogen Phosphate (ADP)}

Ammonium dihydrogen phosphate $\left(\mathrm{NH}_{4} \mathrm{H}_{2} \mathrm{PO}_{4}\right)$, or ADP, reacts with magnesium oxide in the presence of water in an acid-base reaction.

The recent literature reports that the amount of hydrates increases with the amount of $\mathrm{NH}_{4} \mathrm{H}_{2} \mathrm{PO}_{4}$ and, therefore, the strength of magnesium phosphate cement-based binder (MPB) paste theoretically increases ${ }^{12}$. The ADP presented a specific surface area $0.68 \mathrm{~m}^{2} \cdot \mathrm{g}^{-1}$, unitary mass of $0.79 \mathrm{~kg} \cdot \mathrm{dm}^{-3}$ and specific gravity of $1.87 \mathrm{~kg} . \mathrm{dm}^{-3}$.

\subsubsection{Grinding dust}

The automotive industry generates large quantities of a variety of wastes. These include grinding dust, a hazardous waste (class I) generated in the clutch disc finishing process by grinding and polishing. The material is particulate and quite complex due to its diverse constituents (metallic and polymeric fibers as well as fiberglass).

Grinding dust was supplied from ZF Sachs of Brazil factory, São Bernardo do Campo, Brazil. It had a specific surface area $1.32 \mathrm{~m}^{2} \cdot \mathrm{g}^{-1}$ and specific gravity $2.08 \mathrm{~kg} \cdot \mathrm{dm}^{-3}$. Its grain size distribution curve is provided in Figure 2.

\subsubsection{Boric acid}

Retardants have been found to increase the setting time and reduce the intensity of exothermic reactions during the initial setting 
and hardening stages. Therefore, chemical retardants are utilized in large-scale mixing operations. Boric acid containing about $99.5 \%$ of $\mathrm{H}_{3} \mathrm{BO}_{3}$ was used in this study.

\subsubsection{Sodium Tripolyphosphate (STPP)}

The incorporation of sodium tripolyphosphate $\left(\mathrm{Na}_{5} \mathrm{P}_{3} \mathrm{O}_{10}\right)$, or simply STPP, into the magnesium phosphate mixture has a beneficial effect. The deflocculating characteristics of tripolyphosphate ions suggests that they may play a significant role in enabling improved compaction of the wet mix, reducing the porosity of the hardened material ${ }^{13,14}$. Moreover, Abdelrazig et al. ${ }^{14}$ reported that the incorporation of STPP in mortars brought about an increase in compressive strength and a decrease in total and coarse pore volumes.

\subsubsection{Sand}

Sand was supplied from river deposit, commercially available in São Carlos, Brazil. It had a specific surface area $0.68 \mathrm{~m}^{2} . \mathrm{g}^{-1}$ and specific gravity $2.70 \mathrm{~kg} . \mathrm{dm}^{-3}$. Its grain size distribution curve and chemical composition are provided in Figure 3 and Table 1, respectively.

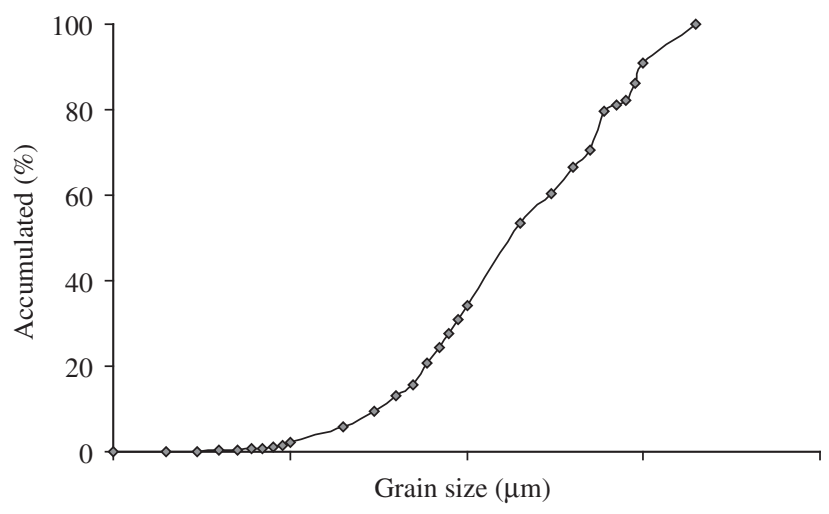

Figure 2. Particle size distribution of the grinding dust used in the tests.

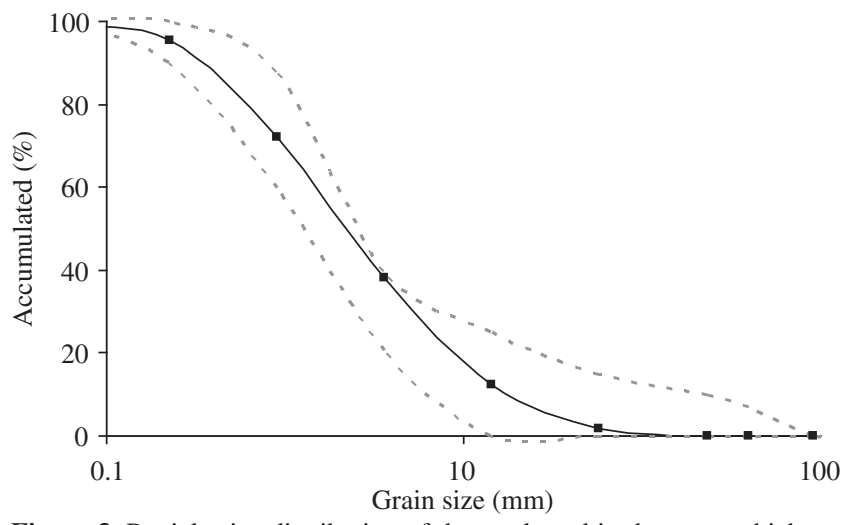

Figure 3. Particle size distribution of the sand used in the tests, which was classified as "fine sand", according to NBR 7211 standard.

\subsection{Methods}

\subsubsection{Mechanical strength}

The values of axial compression and traction by diametral compression correspond to the average of 3 values for each magnesium phosphate mortar age (3, 7 and 28 days after molding), and were obtained with an Instron 5500R universal testing machine and a load of $1.5 \mathrm{~mm} / \mathrm{min}$. The values that differed by more than $5 \%$ from the average were discarded and were substituted for the results of new samples.

\subsubsection{Scanning Electron Microscopy (SEM)}

Test pieces of magnesium phosphate cement samples were fixed on bronze mounts and coated with a thin layer of gold. The coated specimens were then examined employing a Zeiss ${ }^{\circledR}$ DSM 940-A Scanning Electron Microscope, using a tension of $25 \mathrm{KV}$ and work distance $15 \mathrm{~mm}$.

\subsubsection{Water absorption by capillarity}

Checking the water absorption by capillary of the mortar is very important because excessive absorption of water can generate the proliferation of fungi and bacteria harmful to the user, in addition to other problems such as detachment of mortar or coating and stripping the paint.

The specimens used in the test, in a number total of 3, all had 28 days of age. The procedure was carried out according to the NBR 9779 standard. The capillary absorption coefficient is thus estimated, which represents the weight of water absorbed by square meter of mortar in contact with water according to the square root of time to reach this level of absorption. Numerically, this value corresponds to the slope of the plot straight from the "absorption $\left(\mathrm{kg} . \mathrm{m}^{-2}\right) \mathrm{X}$ square root of time (minutes ${ }^{0.5}$ )" graph until it reached the point of saturation, as can be seen in Figure 4.

\subsubsection{Dosage and preparation of sample}

The raw materials were physicochemically characterized and the ratio among the components was determined, in weight. The

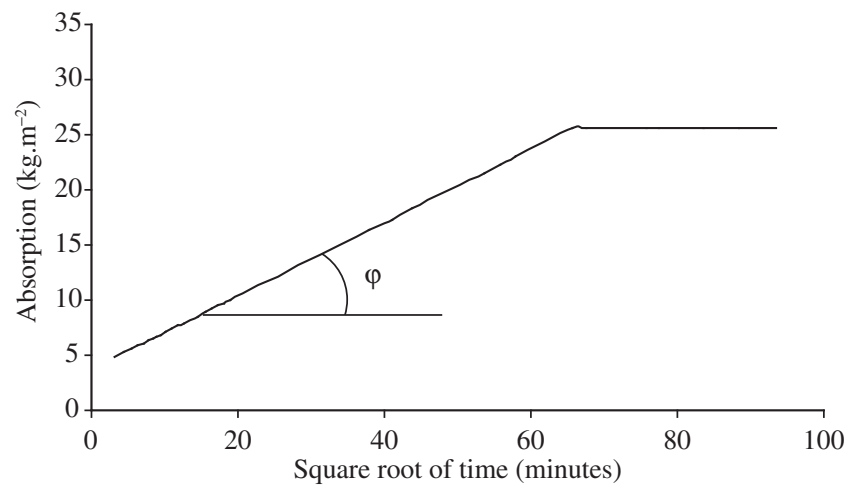

Figure 4. Model of "capillary water absorption $\left(\mathrm{kg} \cdot \mathrm{m}^{-2}\right) \mathrm{x}$ square root of time $\left(\min ^{1 / 2}\right)$ " up to the point of saturation, according to the NBR 9779 standard for the determination of capillary absorption coefficients $(\tan \varphi)$.

Table 1. Equivalent mineral oxide composition of the sand used in the mortars.

\begin{tabular}{ccccccccc}
\hline Component & $\mathrm{SiO}_{2}$ & $\mathrm{Al}_{2} \mathrm{O}_{3}$ & $\mathrm{Fe}_{2} \mathrm{O}_{3}$ & $\mathrm{CaO}$ & $\mathrm{Na}_{2} \mathrm{O}$ & $\mathrm{K}_{2} \mathrm{O}$ & $\mathrm{TiO}_{2}$ & $\mathrm{LOI}^{*}$ \\
\hline Content $(\%)$ & 95.33 & 1.91 & 0.64 & 0.20 & 0.15 & 0.91 & 0.32 & 0.47 \\
\hline
\end{tabular}


"reference proportion" used in the molding of the specimens was 1.0: 0.75: 0.10: 0.30: 0.50 (or 1.0): 0.50 (MgO: ADP: boric acid: STPP: sand; $\left.\mathrm{H}_{2} \mathrm{O}\right)$. Cylindrical specimens of magnesium phosphate cement containing different amounts of grinding dust (0 to $30 \%$ in weight) were molded. After curing in a mold for 1 day at $20 \pm 1^{\circ} \mathrm{C}$, the samples were demolded and cured in air at $20 \pm 1^{\circ} \mathrm{C}$ and relative humidity $70 \pm 5 \%$.

\section{Results and Discussion}

\subsection{Mechanical strength}

The initial mechanical strength of magnesium phosphate mortars with added grinding dust increased up to a limit (of about 30\%) as the waste content increased. This behavior held true for both axial compressive strength and tensile strength under diametral compression, as illustrated in Figures 5 and 6.

As Figure 5 indicates, the mortars showed higher values of strength over time, as expected, particularly with higher sand content, contrary to the findings of Yang et al. ${ }^{15}$ and Ding $\& \mathrm{Li}^{16}$, who suggested that the compressive strength of MPB mortar decreases as the sand/ cement ratio increase, regardless of the curing age.

The aforementioned researchers declared that the strength of MPB mortar declines significantly with increased sand/MPB ratio, when the hydrates are unable to completely envelop nonhydrated $\mathrm{MgO}$ and quartz sand grains. Moreover, an increase in sand content causes a reduction in the volume of paste in the specimen, increasing the interfacial region and leading to lower strength.

Of course, the higher the $\mathrm{ADP} / \mathrm{MgO}$ ratio in the composite the higher the amount of hydrates, thus allowing more sand to be surrounded by these hydrates. These researchers used $\mathrm{ADP} / \mathrm{MgO}$ ratios of 0.25 to 0.33 (Yang et al. ${ }^{15}$ ) and 0.33 to 0.50 (Ding \& $\mathrm{Li}^{16}$ ), with water $\mathrm{MgO}$ ratios varying from 0.13 to 0.21 and from 0.16 to 0.21 , respectively.

In the present work, we used an $\mathrm{ADP} / \mathrm{MgO}$ ratio of 0.75 and a water $/ \mathrm{MgO}$ ratio of 0.50 in all the mixtures. Thus, the large amount of nonreacted water, which does not readily evaporate, participated in the wetting of these additional sand grains, which had a larger quantity of hydrates to envelop them because of the high ADP/MgO ratio.

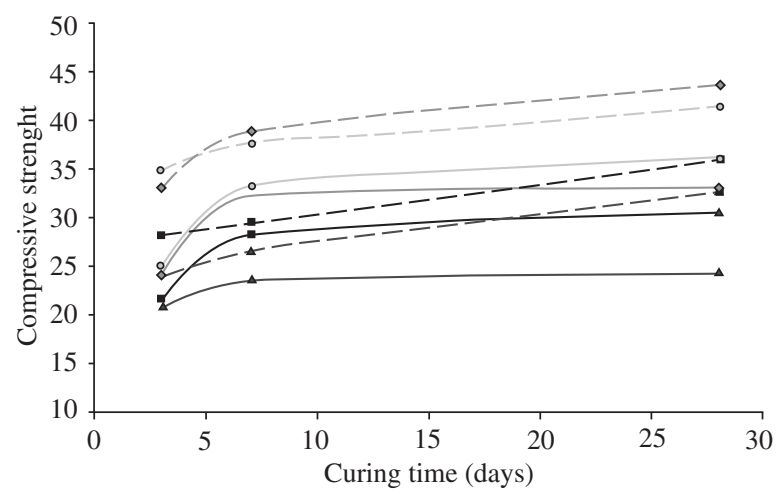

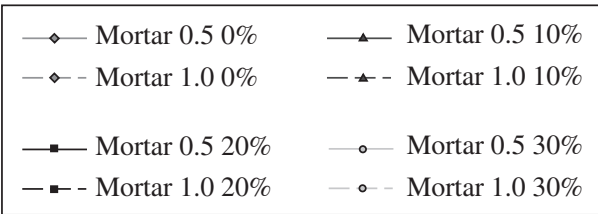

Figure 5. Compressive strength of magnesium phosphate cement mortar as a function of sand and grinding dust contents.
This behavior can be attributed to a combination of two factors:

1) Reduction of the water/solids ratio (w/s) due to the progressive increase of waste content, leading to increased strength ${ }^{14,15}$. This increase, in turn, may result from the higher density of the compositions in response to greater grinding dust content and better particle packing.

2) Interaction between advancing microcracks and the inorganic phase particles in the shape of elongated rods (waste). Microcracking normally begins in the matrix phase, and its propagation is hindered or delayed by waste particles. These particles can inhibit the propagation of microcracks by deflecting their tips, forming bridges through the phases of microcracks and absorbing energy as the particles separate from the matrix and/ or inducing a redistribution of stresses in regions adjacent to the tips of the microcracks ${ }^{17,18}$.

The tensile strength under diametral compression indicated that the influence of the effective bond between sand and paste and the increase in the interfacial region resulting from higher sand content is greater in brittle materials. Thus, as can be seen in Figure 6, the differences between mortars with different sand contents are minor when compared with the results of the axial compressive strength, which showed higher strength for the mortar with a 0.5 sand content, without the presence of waste, and at 28 days for the mortar containing $30 \%$ of waste.

\subsection{Capillary water absorption}

The 28-day-old specimens were subjected to a capillary water absorption test to ascertain their water absorption behavior, which is one of the most important parameters for evaluating mortar performance.

The specimens were weighed following the NBR 9779 standard to determine the angular coefficients of the adjusted straight lines, which mathematically represent the capillary absorption coefficients. Table 2 lists the values of these coefficients and their reliability $\left(\mathrm{R}^{2}\right.$ - correlation coefficient). These values represent the average of 3 specimens for each measure, which all fell within the range of permissible error in this work $(5 \%)$.

For a clearer view, the results were plotted and are shown in Figure 7 . Note that the capillary absorption coefficient decreased
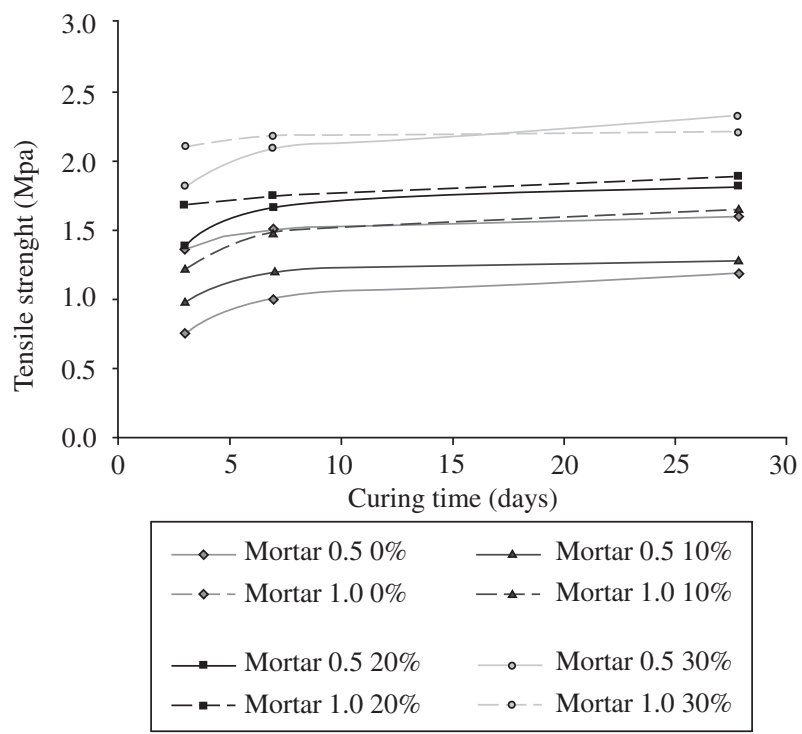

Figure 6. Tensile strength under diametral compression of magnesium phosphate cement mortar as a function of sand and grinding dust contents. 


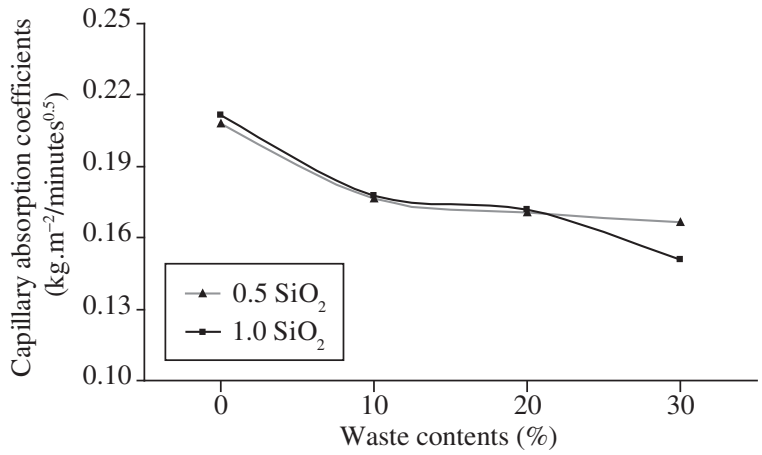

Figure 7. Capillary absorption coefficients of magnesium phosphate cement mortar as a function of sand and grinding dust contents. as a function of increasing amounts of added waste, which reduced the material's porosity, augmenting its density and thus reducing its water absorption. The values varied little in response to sand content, showing a variation only with $30 \%$ of waste content. Although a higher sand content fills more empty spaces in the mortar, a lower sand content allows for a relatively larger waste content, so the empty spaces end up being equally filled.

\subsection{Scanning Electron Microscopy (SEM)}

The microstructure of the reference mortar $(0 \%)$ and of the composites containing added grinding dust (10, 20 and 30\%) were analyzed by scanning electron microscopy after 28 days of curing to check the dispersion of sand and waste particles in the matrix. Figure 8 shows the corresponding micrographs. Micrographs (a),

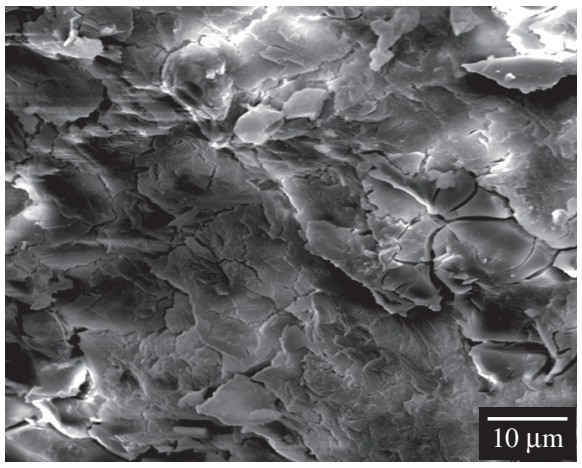

(a)

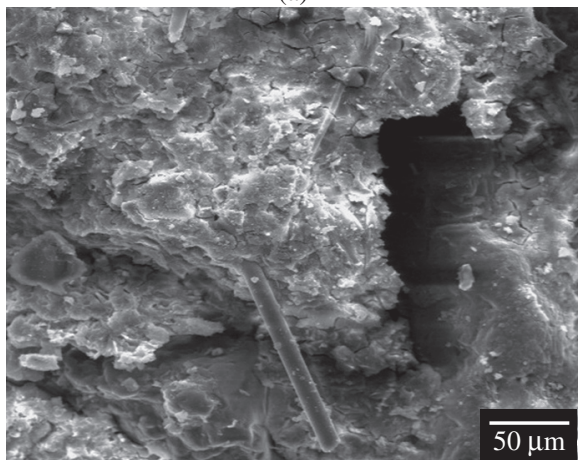

(d)

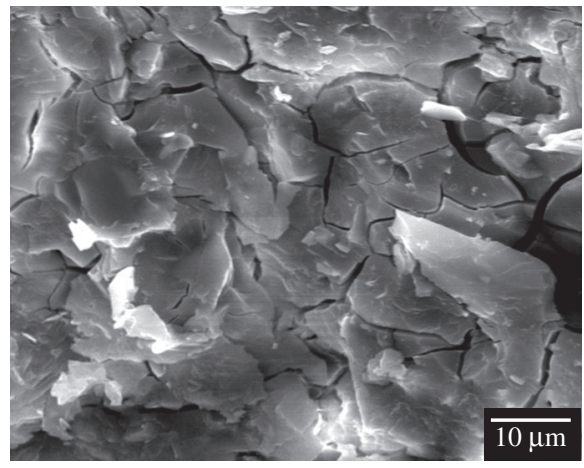

(b)

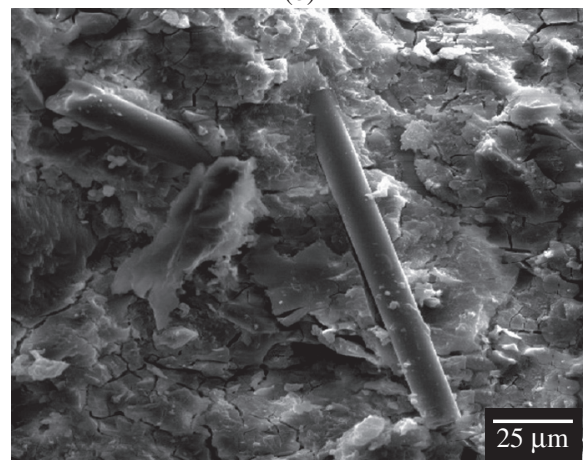

(e)

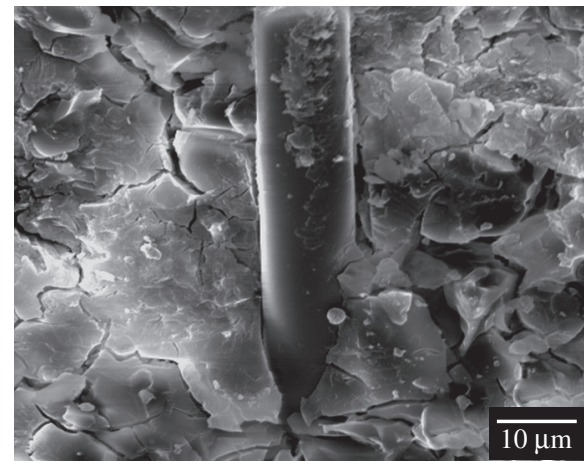

(c)

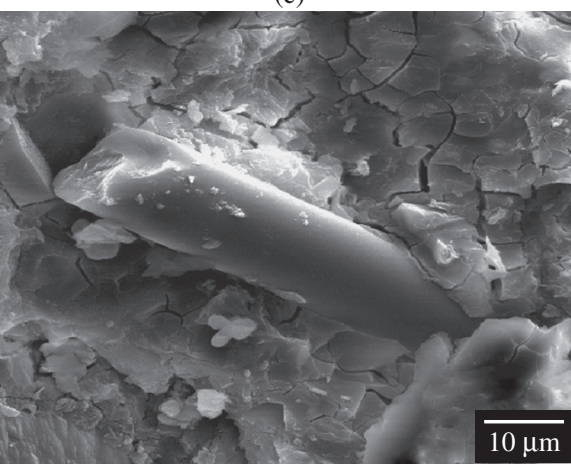

(f)

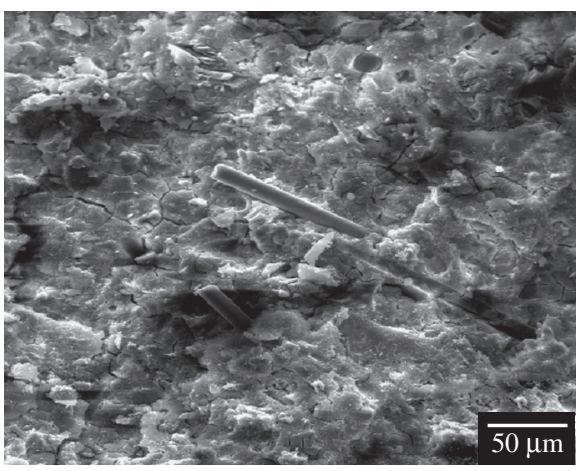

(g)

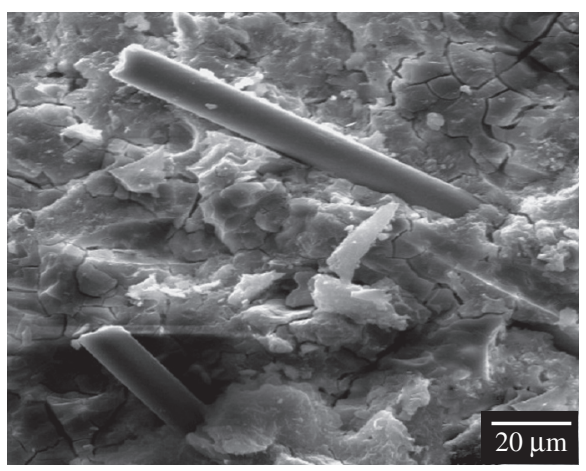

(h)

Figure 8. SEM micrographs of magnesium phosphate mortar with varying amounts of added grinding dust: a) and b) $0 \%$; c) and d) $10 \%$; e) and f) $20 \%$; g) and h) $30 \%$.

Table 2. Capillary Absorption Coefficients $(\tan \varphi)$ of magnesium phosphate cement mortar as a function of sand and grinding dust contents and reliability $\left(\mathrm{R}^{2}\right.$ - correlation coefficient).

\begin{tabular}{|c|c|c|c|c|c|c|c|c|}
\hline \multirow[t]{2}{*}{ Mortar mixture } & \multicolumn{2}{|c|}{$0 \%$} & \multicolumn{2}{|c|}{$10 \%$} & \multicolumn{2}{|c|}{$20 \%$} & \multicolumn{2}{|c|}{$30 \%$} \\
\hline & $\tan \varphi$ & $\mathrm{R}^{2}$ & $\tan \varphi$ & $\mathrm{R}^{2}$ & $\tan \varphi$ & $\mathrm{R}^{2}$ & $\tan \varphi$ & $\mathrm{R}^{2}$ \\
\hline Mortar $0.5 \mathrm{SiO}_{2}$ & 0.21 & 0.98 & 0.18 & 0.99 & 0.17 & 0.99 & 0.17 & 0.99 \\
\hline Mortar $1.0 \mathrm{SiO}_{2}^{2}$ & 0.21 & 0.99 & 0.18 & 0.98 & 0.17 & 0.99 & 0.15 & 0.99 \\
\hline
\end{tabular}


(c), (e) and (g) illustrate the mortar with a $\mathrm{SiO}_{2}$ content of 0.5 , while (b), (d), (f) and (h) correspond to the mortar with a $\mathrm{SiO}_{2}$ content of 1.0 .

The only difference found among the samples was a greater concentration of waste particles in the compositions containing higher waste content, as well as the presence of sand grains dispersed in the matrix of those compositions. The SEM analysis also revealed agglomerated $\mathrm{MgO}$ grains in areas adjacent to sand grains. The presence of a sand grain and $\mathrm{MgO}$ agglomerates dispersed in the matrix is depicted in Figure 9.

\section{Conclusions}

The analyses of the microstructure (SEM), mechanical strength and capillary water absorption led to the following conclusions:

- The presence of grinding dust caused an initial decline in strength, which thereafter recovered with successive additions of waste;

- Increased sand content augmented the mechanical strength of the mortar. This was due to the fact that the large amount of free water, which does not readily evaporate, contributed to wet the added sand grains, which had a larger quantity of hydrates to envelop them because of the high adp/mgo ratio. Moreover, a higher sand content decreased the water/dry solids ratio, increasing the density and reducing the porosity and thus contributing to increase the material's mechanical strength.

- The tensile strength under diametral compression indicated that the influence of the effective bond between sand and paste and the increase in the interfacial region resulting from higher sand content was more pronounced.

- The capillary absorption coefficient decreased as a function of increasing amounts of added waste, which reduced the material's porosity, augmenting its density and thus reducing its water absorption.

- The addition of grinding dust to magnesium phosphate cement mortar probably does not influence the formation of new phases.

\section{Acknowledgements}

- FAPESP - Fundação de Amparo à Pesquisa do Estado de São Paulo

- PPGCEM-UFSCar — Programa de Pós-Graduação em Ciência e Engenharia de Materiais da Universidade Federal de São Carlos.

- ZF SACHS do Brasil Ltda.
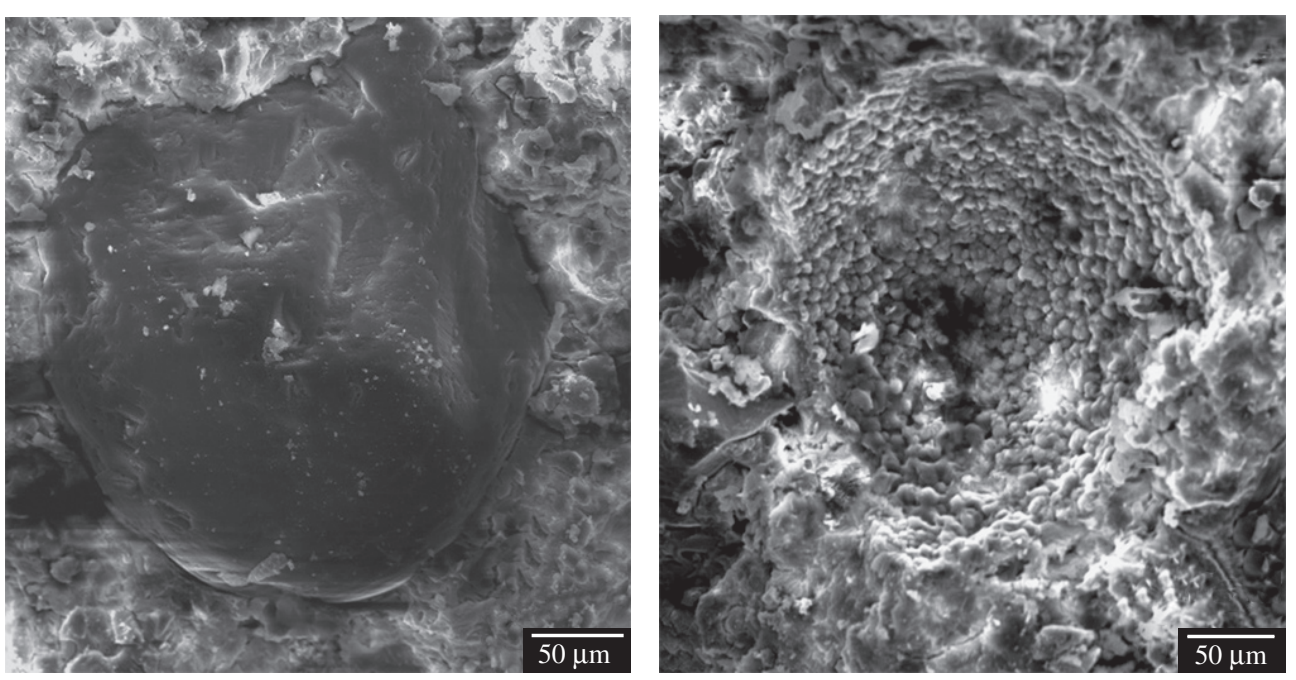

Figure 9. SEM micrographs: a) sand grain dispersed in magnesium phosphate mortar matrix; and b) $\mathrm{MgO}$ grains agglomerated in a region near a sand grain.

\section{References}

1. Sarkar AK. Phosphate cement-based fast-setting binders. Ceramic Bulletin.

2. Roy D. New strong cement materials: chemically bonded ceramics. Science. 1987; 235(4789):651-658.

3. Wagh AS, Singh D, Jeong SY. Chemically bonded phosphate ceramics: a dissolution model of formation. Journal of the American Ceramic Society. 2003; 86(11):1838-1844.

4. Soudée E, Péra J. Mechanism of setting reaction in magnesia: phosphate cements. Cement and Concrete Research. 2000; 30(2):315-321.

5. Sarkar AK. Hydration/dehydration characteristics of struvite and dittmarite pertaining of magnesium ammonium phosphate cement systems. Journal of Materials Science. 1991; 26(12):2514-2518.

6. Ribeiro D.V., Morelli M.R. Resíduos Sólidos: problema ou oportunidade? Rio de Janeiro: Interciência; 2009. 160 p.

7. Argonne National Laboratory. Chemically bonded phosphate ceramics for stabilization and solidification of mixed waste. Available from: $<$ http://www.techtranfer.anl.gov/techtour/ceramicrete-pubs.html>. Access in: 2005 December 15.

8. Double DD. Chemically bonded ceramics: taking the heat out of making ceramics. Journal of Materials Education. 1990; 12(2):353-381.

9. Sant' anna JAP, Morelli MR. Massas moldáveis de rápido endurecimento. In Annals of the $41^{\circ}$ Congresso Brasileiro de Cerâmica; 1997; São Paulo. São Paulo: Associação Brasileira de Cerâmica; 1997. p. 809-813.

10. Sant' anna JAP, Morelli MR. Chemically bonded $\mathrm{MgO}$ mouldable ceramics. Acta Microscopia. 1998; 7(supl. A):41-44.

11. Shelley T. Moldable ceramics challenge plastics. Eureka on Campus. 1992.

12. Kingery W. Fundamental studies of phosphate bonding in refractories. II. Cold Setting Properties. Journal of American Ceramic Society. 1951; 33(8):239-250.

13. Abdelrazig BEI, Sharp JH, El-Jazairi B. The chemical composition of mortars made from magnesia: phosphate cement. Cement and Concrete Research. 1998; 18(3):415-425.

14. Abdelrazig BEI, Sharp JH, El-Jazairi B. The microstructure and mechanical properties of mortars made from magnesia: phosphate cement. Cement and Concrete Research. 1989; 19(2):247-258.

15. Yang Q, Zhu B, Zhang S, Wu X. Properties and applications of magnesiaphosphate cement mortar for rapid repair of concrete. Cement \& Concrete Composites Journal. 2000; 30(11):1807-1813.

16. Ding Z, Li Z. Effect of aggregates and water contents on the properties of magnesium phospho-silicate cement. Cement \& Concrete Composites Journal. 2005; 27(1):11-18.

17. Callister Jr WD. Ciência e Engenharia de Materiais: uma introdução. 5 ed. Rio de Janeiro: LTC; 2002.

18. Smith WF. Princípios de ciência e engenharia dos materiais. 3 ed. Lisboa: Mc-Graw Hill; 1998. 1995; 69(2):234-237. 